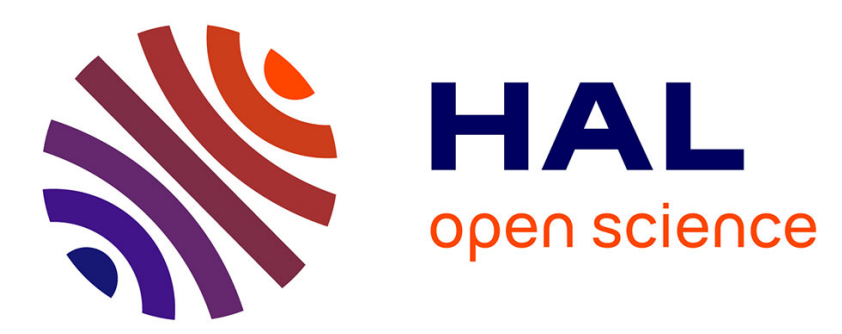

\title{
Assistance to building construction coordination by images
}

\author{
Sylvain Kubicki, Gilles Halin, Jean-Claude Bignon
}

\section{To cite this version:}

Sylvain Kubicki, Gilles Halin, Jean-Claude Bignon. Assistance to building construction coordination by images. Conférences ECPPM, Sep 2004, Turquie. pp.1-6. halshs-00267856

\section{HAL Id: halshs-00267856 \\ https://shs.hal.science/halshs-00267856}

Submitted on 28 Mar 2008

HAL is a multi-disciplinary open access archive for the deposit and dissemination of scientific research documents, whether they are published or not. The documents may come from teaching and research institutions in France or abroad, or from public or private research centers.
L'archive ouverte pluridisciplinaire HAL, est destinée au dépôt et à la diffusion de documents scientifiques de niveau recherche, publiés ou non, émanant des établissements d'enseignement et de recherche français ou étrangers, des laboratoires publics ou privés. 


\title{
Assistance to building construction coordination by images.
}

\author{
KUBICKI Sylvain ${ }^{\dagger}$ \\ MAP-CRAI. (Research Centre in Architecture and Engineering, Nancy, France.)
}

HALIN Gilles ${ }^{\dagger}$

MAP-CRAI. (Research Centre in Architecture and Engineering, Nancy, France.)

BIGNON Jean-Claude ${ }^{\dagger}$

MAP-CRAI. (Research Centre in Architecture and Engineering, Nancy, France.)

${ }^{\dagger}\{$ kubicki, halin, bignon $\} @$ crai.archi.fr

\section{ABSTRACT:}

This communication describes a research theme about new tools to assist architectural design and building construction focus on the use of imagery. The article focuses on specificities of architectural design and building construction stage as collaborative activities. We suggest here two different potentialities of building site imagery. The first consists in a use to assist coordination between actors during construction stage, while the other one describes specificities of a knowledge management tool (pathology prevention assisted by images). We present finally the prototype set up to illustrate meeting reports and diffuse information to the operation's actors.

\section{INTRODUCTION.}

Nowadays, many changes have happened in the AEC sector concerning concurrent engineering work methods. Many studies attempt to characterize specificities of project and design in architecture, in order to introduce new tools.

This article is part of the concurrent engineering research works of CRAI (Nancy School of Architecture). We present here a research theme, which is an extension of works on tools propositions for architectural design concurrent activity. These works also studied the role of images in architectural design. Our communication focuses on the use of building construction digital imagery.

We will describe the specificities of architectural design activity and particularly the differences between "initial and technical design" in architecture and the building construction stage. These first statements will allow us to describe how the image can assist these activities in which many actors are involved.

We will suggest a method to build and use a building construction image base, describing relevant information needs. We will talk about image collection problems (sources, index methods) and about possible uses of these images in coordination (or communication) and in knowledge management.

We will present in the next part the experiment being developed at the moment, which will illustrate the meeting reports. Our goal is to use the images as a communication tool (around the meeting report) and to manage technical information thinking of fu- ture uses (building site image based system to prevent construction anomalies).

Finally, we will talk about recent evolutions and conclude on these works.

\section{ARCHITECTURAL DESIGN AND BUILDING CONSTRUCTION ACTIVITIES.}

The architectural design is the object of many works aiming at appreciating its specificities as design activity [Simon 1990, Al Hassan 2002]. Building works construction develops specific problems too that we will attempt to characterise here.

Our general research goal is to suggest new tools to assist these activities. We are particularly interested in collaboration around design and construction stages. We will now describe particularities of these two activities of the architectural project and used tools.

\subsection{Architectural and technical design stage.}

Architectural design is the place where a creative activity encounters an engineering activity (technical or user constraints). Design is generally supervised by the architect, first project designer, commissioned by the client. The architect surrounds himself with other specialist actors to resolve and anticipate project aspects that he can't master such as technical design (structure, fluids...). 
Architectural design activity consists of a mechanism of proposition-validation of solutions between actors, in order to find a satisfying solution to the building project. Exchange documents are principally plans, technical notes or schemes. This stage can be assisted by specific "profession tools" (e.g. CAD tool for architects). Groupware tools can assist collaboration between designer teams. These tools allow users to group documents or to manage the tasks of each participant. During the first stage of the project, actor coordination is very often implicit because there are not many actors and those who exist know each other well. Work mode is coupled and actors work principally in a synchronous way.

\subsection{Building construction stage.}

This first stage of the project described above in is followed by the building contractors 'consultation. Then comes the building construction stage.

During this stage, the three actor groups described before stay stable. The client role is resumed in a building work progress validation task. The design team often engaged a coordinator, responsible for task realisation progress. The work group expands and includes every building contractor. Actor relations become more hierarchical and distant because of the aim of respecting deadlines and costs. Work and data exchange is made sequentially and actor meetings are based on validation of an asynchronous work. The principal tool for assisting this stage is the "building construction meeting report", great link and communication tool between actors. It contains textual information and progress charts which help everybody in task realisation comprehension. There are not many computer-based tools employed to assist this stage in the AEC domain. But we think that the sequential character of activity during building construction is propitious for the integration of workflow tools (task management, materials supply...).[McCready 1992]

This work mode is the result of a gap existing between different actors: there is no durable link between them. This is due to the re-composition of teams at each project and to the coordination mode based on contracts. This characteristic penalizes the group because actors use specific tools!

\subsection{Design assistance tools.}

Characteristics of architectural project collaborative activity described here have been analysed in works developed in the MAP-CRAI [Malcurat 2001, Hanser 2003]. A model representing the variety these exchanges has been proposed following a logic guided by the "representation of relations between actors, activities and documents during the project" [Hanser 2003].

More other, we are at present seeing the development of quality charts: designers and architecture studios need methods and tools to assist them...

In this context, reflexions about new tools are based on two principles:

- Architectural design assistance to increase project quality,

- Assistance to the collaborative work between design/construction teams based on appropriate tools (communication and project management quality).

In part IV, our propositions are developed on these two basic principles.

\section{THE IMAGE.}

The image is, nowadays, a support largely used to carry information. The reasons for the efficiency of the image are well known and numerous. We are particularly interested in the following characteristics:

- Considerable physiological sensibility of the person whose perception is predominated by visual images,

- Great aptitude to memorization of images,

- Great capacity of image encoding,

- Instant global message,

- Proof effect,

- Iconic seduction.

[Bignon 2002]

\subsection{The image in architectural design.}

Image plays an important role in architectural design mechanisms. It's both the first material of creation and a tool to comprehend a problem. It's also the principal media used to transmit architectural doctrines. This visual culture of architects leads them to develop a specific meaning called "visuo-spatial" [Gardner 1992]. In this specific work practice, meaning mechanisms are very often built by image.

Research works have been developed in MAP-CRAI around this theme. Their objective is to study the possible uses if images to access information during the architectural design process: from idea emergence to project realisation.

According to the moments of design, the image can play different roles. We are interested here in two major functions: the image as reference (in the early stage of design) and the analogous image (the designer will search for and identify possible solutions by making correspondence between the image of an object or a work and the imagined solution to a project.) [Halin et al. 2003]. 
A study of the use of image as information search support has been developed to access building product information [Nakapan 2003].

The information search by image uses image search for "user needs" formulation. The user formulates his request by choosing or rejecting images. This request is analysed to permit products selection. This process needs to use a common ontology for image index and product index.

We introduce here a particular work issue based around building construction images.

\subsection{Building construction images benefits.}

The particularity of building construction image is that it shows an object being fabricated.

We must distinguish between two different uses:

Image illustrates the building construction's general progress, or particular "works under construction". (Note: We called "work under construction" a basic part of the building being built). In this case, image plays a proof role.

Image can transmit information contained or be a tool to access other related information (illustrated by images). It therefore enables the user to capitalise on knowledge of the terrain.

\subsubsection{Works realisation proof.}

Generally, the photo taken of the building construction site at a precise moment is a building construction progress statement. Image is proof of this progress and can be used in different cases (actor communication, archiving...).

We introduce here a relation between particularities of images taken on building site and the "building construction meeting report". This document is the basis of the coordination in the building construction stage. A brief analyse of its content permits us to find the same notions: particular work progress statement, building work or actor interface details).

Nowadays photos sometimes illustrate meeting reports. Architects largely accept the role of image to increase communication quality but not everyone agrees on its regular use in the meeting report. There is some opposition to these propositions, such as some architect wish to produce short meeting reports.

We characterise this particular use of building construction images as a vector enabling a project realisation context. We can note too that a particular objective of the setting up of quality charts is the necessity for each actor to globally understand the context of its intervention. Taking into account this environment (global work progress, actor interfaces) lead to the auto coordination of actors.

Now we will see how these building construction images can serve knowledge management tools.

\subsubsection{Capitalisation of a terrain knowledge.}

An image base built and used in the building construction stage must be completed by semantic information. Every future use is conditioned by the development of an index ontology (based on coordination).

We suggest two different levels: knowledge comprehension assistance (e.g. image as representation of a specific problem) and image as a guide to link the user to other information.

Using the image to represent a phenomenon or an object is not innovative. We would say here that such practices are current among architects, who take photos of their realisation or building site. Their goal is to capitalise knowledge and skill. The use of an index method will allow future search in the image base (e.g. precise operation or particular work image search).

Based on these propositions, we suggest using image in order to formulate a request, and so assisting the designer when he is not able to formulate a design problem (vague need) for himself. The interest of search by image in architectural design activity and particularly of assisting a vague problem formulation has been developed in a PhD work [Nakapan 2003]. The request formulation assisted by image could guide the user to other information (the content of this information is to define in relation to image specificities).

\section{PROPOSITION OF A METHOD AROUND THE MEETING REPORT.}

A tool has been developed to experiment the use of image in a construction operation.

\subsection{Objectives.}

We have set up a tool allowing users to illustrate the meeting report by images of the construction operation.

A study of the meeting report general structure has been developed in order to define exactly the experimental context. We have made fundamental hypotheses. Independently of the form of the document, we can target in its structure two types of information that interest us directly: the progress notion and the particular points. General construction progress relates to tasks or particular work realisation. Particular points refer to details or comments about a specific work. The model presented (Fig 2) explains the constitution of the document and the different parts that comprise it. Our proposition consists of illustrating the information of "progress points" and "particular points". 


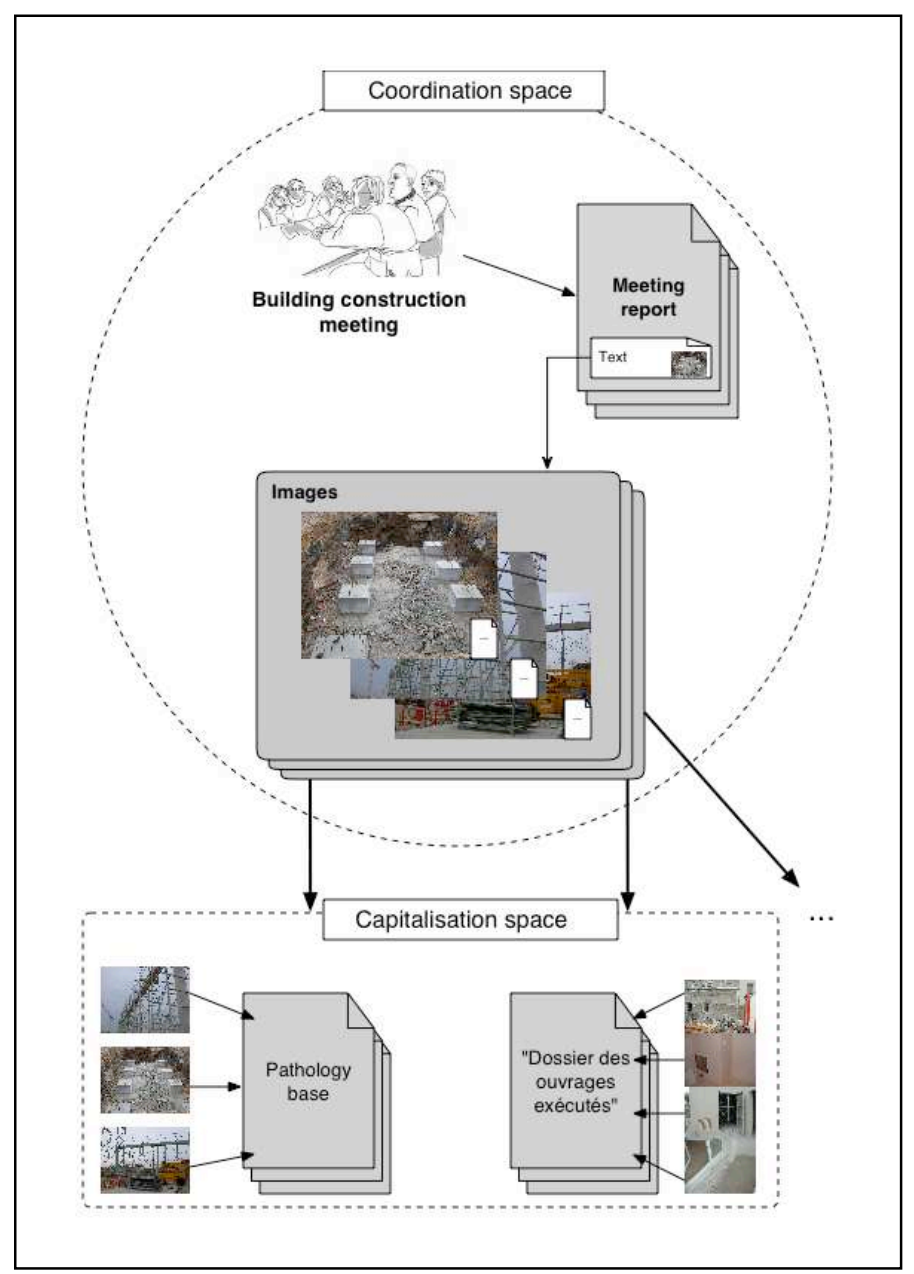

Figure 1 : Experiment principle.

The textual information illustrated by the image becomes our index source. The content of the text is linked to the concepts of task (activity), actor and document (a point concerning a specific document, e.g. plan). The specificity of the AEC domain implies the notion of "built work" which is present in all information on the meeting report.

Figure 1 is a general scheme of the method developed. It represents the two different spaces of image uses: coordination and capitalisation.

Figure 2 presents the conceptual data model of the meeting report document. We will describe the prototype developed based on this model.

\subsection{Experiment description through model description.}

First, the model represents the structure generally observed of the meeting report document: actors presence table, general observations, particular points and progress points (or table). We suggest illustrating particular and progress points with an image that will be indexed in relation to the point content.

The implementation of this model in a database has allowed the development of a meeting report tool interface. At present, the index stage is "manual", the user must choose index terms in two categories: "build work" and "actor". In the future, we envisage text analysis functions to allow a direct concept extraction from the meeting report text. In the context of this experiment we are doing the data capture but we are developing too a user-friendly interface in order to define a meeting report assistance tool for building construction coordinators.

\subsection{Scenarios of use by building construction actors.}

We have set up a web server to diffuse our parallel meeting report to each participant. Users can consult the basis of the meeting reports related to their intervention.

For each point in the meeting report, an image can be visualised (small view or big image download). A contextual menu on the image sends users to other images by "proximity criteria" that we will now describe:

- "Work under construction" statement proximity. The tool suggests displaying images of the same building work on previous progress states (e.g. week before).

- The geographical proximity of built work. With such a function, the user can identify other works in the same area at a specific time (e.g. before, at the same time or coming later). For example it allows the identification of interfaces between actors and risks.

- Actor's proximity. Who works in the same area? What building works are concerned? Etc. We think that such information will develop the consciousness of a common work and increase communication between actors.

Our hypothesis is that these dynamic navigation functions will allow the user to obtain contextual information about the building project and better situate his own intervention.

In our experiment, this function of "proximity" search around images will allow us to better evaluate the potential of images such as a project context visualisation help tool. How can image serve building progress while allowing or increasing the actors auto coordination?

Figure 3 shows a view of the web user interface developed (the visualisation of a meeting report).

\subsection{First assessment.}

The research work presented here has been approached in different ways. An investigation among architects has allowed us to analyse their needs and their attempts concerning new tools.

This investigation has shown a real interest in the use of photography, and everybody agrees with its technical character. On the other hand, we have noted the existing needs and the interest in new 




Figure 2: Meeting report data model.

computer-based tools to assist design and realisation teams.

The tool developed is in an initial statement (prototype). At the present it only allows users to manage "particular points" and "progress points" in the meeting report. In the present version, the user can only insert one image and we notice that it's too limited in some cases. In fact, for some details two photos could increase the comprehension: a large view of the building work and a "closed" view of the detail.

Concerning the "web user", the interface is in its first version. We simply display information of a point as a table containing a text, a photo and other information (geographical area and progress) (Fig 3 ). We note some limits of the interface. First in the comprehension of areas: a classification by areas would be clearer. Secondly, we envisage graphically signalling the progress statement of a building work, particularly to show the works behind schedule... Finally, we will develop the "proximity links" described above in to increase the dynamic use of the tool.

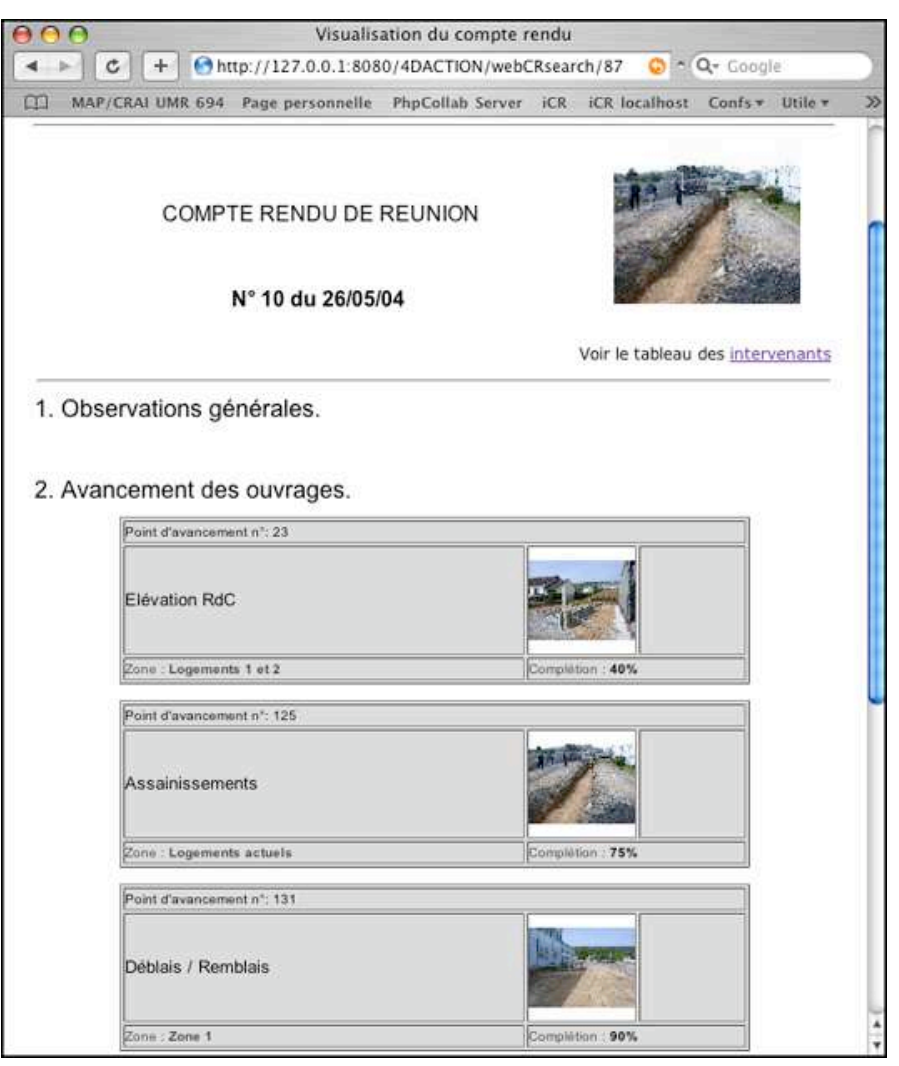

Figure 3 : Web user interface. 


\section{RESEARCH PERSPECTIVES.}

Focusing on coordination around the meeting report we can imagine other methods. The image could be set in relation to a theoretical progress statement (such as a Gantt diagram or digital mock-up) in order to show possible problems in construction progress.

Beyond this proposition of an everyday use of the photo, we immediately notice the bringing-in of this media into the building life cycle. Many ways of thinking are open too in the patrimony management. For example, illustration of building work sequences enables us to keep a trace of what has been made and how it was made... Thus, "building works" construction information can be reused later, particularly when building works are hidden by other works in the final state of the building (e.g pipes passages). We underlined too the interest in image in knowledge management. We are at present setting up the structure of a construction risks prevention tool (called here "pathology prevention"). The "search by image" described in part 3.1 seems to be adapted here to allow the user to access information. The designer could navigate without a precise request and be informed about possible pathologies (function of materials used, build works or actors).

Technically the search engine could answer the requests (formulated by the image) making the link between two ontologies: one indexing image and the other one indexing a pathology case.

\section{CONCLUSIONS.}

Introductive parts of this article show that the study described here follows other research works which allow us to characterise cooperative activity of "design and realisation stages" in the architectural project [Halin, Hanser]. These studies allowed us too to demonstrate the major role of image in architectural design activity as an information vector adapted to the architect cognitive reasoning. [Bignon et al.].

This article presents a research work focused on construction coordination and knowledge management. Our propositions are based on the building construction image or photography as information vector and navigation tool.

We want to demonstrate here the place of image as an accessibility vector to a particular work environment: the building construction. The sequential tasks of building construction, precisely described in many documents (progress charts...) are important characteristics to give sense to images. This temporal aspect is very important for every future use. The information content in the meeting report "particular points" is very interesting too because it introduces the particularity linked to the works building stage: e.g. pathology, risks and defects.
The proposed functionalities of assistance tools follow these two particular properties of images: general progress and particular points. A first proposition consists of tools oriented "building construction coordination" (workflow), and a second type of tool focuses on assisting designers during the initial design stage bringing terrain knowledge (e.g. pathology risks information).

The prototype developed is at present tested on two building sites and will allow us to verify hypotheses described in this article concerning the assistance to the actor coordination by image. A parallel functionality will be developed and available for users concerning the pathology information tool (described in part V).

\section{REFERENCES.}

[Abeid 2003] ABEID (Jorge), ALLOUCHE (Erez), ARDITI (David), HAYMAN (Michael). - Photo-Net II : a computer-based monitoring system applied to project management. - in "Automation in Construction" 12 (2003) 603616. - Elsevier Ed. - 2003.

[Al Hassan 2002] AL HASSAN (F.), TRUM (H.) and RUTTEN (P.) - Strategic Briefing. A Conceptual Process Model for Building Design. - In proceedings of DDSS'O2, 6th Conference, Ellecom, Netherlands, pp: 168-185. - 2002.

[Bignon 2002] BIGNON (J.C.) - Modélisation, simulation et assistance à la conception-construction en Architecture Habilitation à diriger les recherches, Nancy - 2002.

[Gardner 1992] GARDNER (H.) - Multiple Intelligence: The Theory in Practice. - New York, Basic Books. Ed. - 1992.

[Grezes 1994] GREZES (Denis), HENRY (Eric), MICQUIAUX (Dominique), FORGUE (Michel). - Le compte rendu de chantier, rapport final de recherche. - Plan Construction Architecture, 1994.

[Halin et al. 2003] HALIN (G.), BIGNON (Jean-Claude), SCALETSKY (Celso), NAKAPAN (Walaiporn) and KACHER (Sabrina) - Three approaches of the use of image to assist architectural design. - In proceedings of CAADRIA 2003 (Computer Aided Architectural Design Research In Asia), Bangkok, Thaïlande. - 2003.

[Hanser 2002] HANSER (Damien), HALIN (Gilles), BIGNON (Jean-Claude). - Toward a user adaptive vision of architectural projects. Conférence eCAADe, Education in Computer Aided Architecture and Design, p.238-245, Varsovie - septembre 2002.

[McCready 1992] McCready (S.) - There is more than one kind of workflow software. - Computerworld, - November 1992.

[Simon 1990] SIMON (H.A.) - Sciences des systèmes, Sciences de l'artificiel. - Paris, Editions Dunod - 1990. 